\title{
Hierarchical foraging movement of humpback whales relative to the structure of their prey
}

\author{
Theresa Kirchner ${ }^{1,2, *}$, David N. Wiley ${ }^{3}$, Elliott L. Hazen ${ }^{4}$, Susan E. Parks ${ }^{5}$, \\ Leigh G. Torres ${ }^{1}$, Ari S. Friedlaender ${ }^{1,6}$
}

\author{
${ }^{1}$ Department of Fisheries and Wildlife, Marine Mammal Institute, Hatfield Marine Science Center, Oregon State University, \\ Newport, Oregon 97365, USA \\ ${ }^{2}$ Center for Coastal Studies, Provincetown, Massachusetts 02657, USA \\ ${ }^{3}$ Stellwagen Bank National Marine Sanctuary, NOAA National Ocean Service, Scituate, Massachusetts 02066, USA \\ ${ }^{4}$ NOAA SWFSC Environmental Research Division, Monterey, California 93940, USA \\ ${ }^{5}$ Department of Biology, Syracuse University, Syracuse, New York 13244, USA \\ ${ }^{6}$ Institute of Marine Sciences, University of California Santa Cruz, Santa Cruz, California 95060, USA
}

\begin{abstract}
Movement within and between prey patches can influence the fitness of a predator, and understanding such foraging decisions is an important topic in ecology. Most research has found sustained foraging in dense prey patches but has focused on the movement of raptorial predators that feed on single prey items, or suspension-feeders foraging on comparatively immobile zooplankton. The goal of this study was to investigate the fine-scale movement of a suspension-feeding marine vertebrate species while foraging for mobile prey. Using animal-borne tags and surface observations, we analyzed the movement of foraging humpback whales Megaptera novaeangliae within and among acoustically detected patches of sand lance Ammodytes spp. in the water column in the southern Gulf of Maine, USA. Analyzing data from 9 whales tagged between 2008 and 2012, we found hierarchical whale foraging movements that paralleled a complex, hierarchically structured prey landscape. For 7 out of 9 whales, feeding bout scales corresponded to prey patch scales. For 6 out of 9 whales, movement between sequential feeding events was not significantly different from distances between neighboring prey schools. Targeting neighboring schools during sequential feeding events, as opposed to sustained foraging in profitable patches, may increase foraging success in marine suspension-feeders targeting mobile prey, which confirms findings from many other marine predator taxa feeding on mobile prey species. Our study presents novel evidence for the high behavioral plasticity of an intermittent suspensionfeeder targeting mobile prey, adapting its movement to the behavior of its prey and the structure of its prey field.
\end{abstract}

KEY WORDS: Hierarchical analyses · Feeding ecology · Predator-prey interaction · Patchiness · Suspension-feeding $\cdot$ Megaptera novaeangliae $\cdot$ Sand lance

\section{INTRODUCTION}

How animals move within and between prey patches remains an important question in ecology (van Gils et al. 2015). Optimal foraging theory suggests that behavioral strategies lead to a concentration of foraging effort in areas with the highest prey

\footnotetext{
*Corresponding author: tkirchner@coastalstudies.org
}

densities, and a minimization of the time spent transiting between prey patches (Charnov 1976, Pyke et al. 1977). The retention of mobile predators in profitable patches can be achieved through an increase in turning rate and a decrease in movement speed following an initial encounter with prey or prey cues (Benhamou 1992). Such area-restricted search (ARS)

() The authors 2018. Open Access under Creative Commons by Attribution Licence. Use, distribution and reproduction are unrestricted. Authors and original publication must be credited. 
(Kareiva \& Odell 1987) movement has been shown for a variety of predator taxa from lizards (Eifler et al. 2012) to dolphins (Bailey \& Thompson 2006) to blue whales Balaenoptera musculus (Bailey et al. 2009). The foraging activity in the prey patch can continue until the net energy gain from the patch is reduced and the predator moves to the next prey patch, maximizing energetic efficiency by minimizing travel between patches (Charnov 1976). However, where prey distribution is dispersed (Viswanathan et al. 1999, Weimerskirch et al. 2007), or where predator avoidance behavior by the prey can lead to a reduction in patch profitability (Charnov et al. 1976, Sih 1984), remaining in a patch may not be a successful foraging strategy.

The pelagic marine environment is characterized by a complex geometry of resource patches, where small, high-density patches are spatially nested within lower-density patches that occur at broader spatial scales (Steele 1978, Wolanski \& Hamner 1988, Barange et al. 1993, Fauchald et al. 2000). Predators foraging in this environment track their prey on multiple spatial scales in order to gain spatial and temporal overlap with the more energetically profitable smaller patches nested inside the larger, less dense patches. For example, yellow-nosed albatrosses Thalassarche carteri, Antarctic petrels Thalassoica antarctica, murres Uria spp. and northern fur seals Callorhinus ursinus adopt spatially nested foraging strategies to pursue spatially nested prey patches (Fauchald et al. 2000, Pinaud \& Weimerskirch 2005, Fauchald \& Tveraa 2006, Benoit-Bird et al. 2013). Correlations of the scales of predator foraging movement with the scales of prey aggregations illustrate the effectiveness of these spatially nested movements in tracking prey aggregations (Fauchald et al. 2000, Benoit-Bird et al. 2013).

Most studies investigating the foraging movement of marine predators focus on raptorial predators targeting single prey items. In contrast, less is known about finescale foraging movements during suspension-feeding, a highly profitable foraging strategy for the largest marine vertebrates (Friedman et al. 2010). Within this group, continuous and intermittent suspension-feeders can be distinguished depending on whether prey is ingested continuously or in discrete events (Sanderson \& Wassersug 1993). ARS behavior in areas of high prey density has been reported for a variety of continuous suspension-feeding species preying on zooplankton, including basking sharks Cetorhinus maximus (Sims \& Quayle 1998), manta rays Manta alfredi (Papastamatiou et al. 2012) and right whales Eubalaena glacialis (Mayo \& Marx 1990), enabling the predators to remain in profitable areas. Sims \& Quayle (1998) showed that basking sharks use ARS to locate high-density patches of calanoid copepods Calanus helgolandicus, and actively track these profitable patches during their displacement by tidal currents. Their prey is incapable of avoiding predation by basking sharks and is aggregated by currents at speeds that can be followed easily. In contrast, intermittent suspension-feeders that engulf and then filter distinct portions of prey-laden water (Sanderson \& Wassersug 1993) often feed on schooling fish. Because their prey is capable of active predator avoidance behavior (Pitcher \& Parrish 1993), sustained feeding in the same prey patch may be a less viable foraging strategy than rapid patch switching for intermittent suspension-feeders.

Here, we investigated the foraging movement of an intermittent suspension-feeder, the humpback whale Megaptera novaeangliae, within and between patches of mobile prey. In the Gulf of Maine, USA, humpback whales are known to bubble-feed on sand lance Ammodytes spp. in the water column (Wiley et al. 2011). Sand lance are a small schooling fish with a highly patchy distribution that under certain conditions bury into the seafloor (Reay 1970, Robards et al. 1999). In the simplest form of bubble-feeding, the whales dive below a school of fish, form a bubble net around the school by producing air bubbles while ascending and circling the school, and then open their mouth and lunge through the school before closing their mouth and straining the fish from the seawater (Wiley et al. 2011). We tested the hypotheses that (1) sand lance aggregations in the southern Gulf of Maine are spatially nested, and that similarly, (2) a spatially nested structure exists for humpback whale bubble-feeding bouts targeting sand lance schools. To examine the influence of prey field structure and prey behavior on predator foraging movement, we investigated the hypotheses that (3) the sizes of bubble-feeding bouts corresponded to the sizes of sand lance patches, and (4) sequential feeding events target neighboring prey schools, rather than the same school repeatedly.

\section{MATERIALS AND METHODS}

\section{Whale behavior data collection}

Our data come from a long-term research project investigating the foraging behavior of humpback whales in and around the Stellwagen Bank National Marine Sanctuary (SBNMS) in the southern Gulf of 
Maine, USA (e.g. Wiley et al. 2011). Between 2004 and 2015, in June and July, digital acoustic recording tags (DTAGs) (Johnson \& Tyack 2003) were deployed on humpback whales to record their 3-dimensional subsurface movements. DTAGs are minimally invasive motion-sensing archival tags attached to an animal with suction cups and equipped with 3 -axis accelerometers and magnetometers, a pressure sensor, all sampling at $50 \mathrm{~Hz}$, and a VHF transmitter for tracking (Johnson \& Tyack 2003, Wiley et al. 2011). Tag deployment usually occurred in areas where large numbers of whales were aggregated and often foraging. While the main tagging effort targeted whales foraging in groups, tag deployments occurred opportunistically. Tags were deployed from a small rigid-hull inflatable boat (RHIB) using a $7 \mathrm{~m}$ carbonfiber pole (Friedlaender et al. 2009, Wiley et al. 2011). Tag release was programmed to occur within $24 \mathrm{~h}$ of deployment. Focal follows of tagged individuals were conducted during daytime from a RHIB recording detailed observations of the whale's surface behavior (e.g. bubble-feeding, traveling, resting) and associations with other whales during each surfacing (Friedlaender et al. 2009, Hazen et al. 2009, Wiley et al. 2011). Laser-rangefinder measurements of range and bearing of the whale relative to the focal follow boat were taken at least once per surfacing (Hazen et al. 2009). Together with the boat's GPS positions, logged automatically every $10 \mathrm{~s}$, the position of the whale could then be calculated using triangulation for each data point, with a spatial accuracy of approximately $80 \mathrm{~m}$ (M. A. Thompson pers. comm.).

\section{Prey data collection}

The distribution of prey in the water column around tagged whales was measured using calibrated, scientific SIMRAD EK60 echosounders operating at 38 and $120 \mathrm{kHz}$, sampling with a ping rate of 1-10 pings s ${ }^{-1}$ (Hazen et al. 2009). Using towfishmounted echosounders, the prey-mapping ship RV 'Auk' (15 m long catamaran) centered its preymapping effort on the approximate location of the tagged whale, moving several hundred meters away from the whale and then returning to the position of the whale, before moving into a different direction and returning to the whale, thereby sampling the area and moving in a clover-leaf pattern around the tagged whale (Hazen et al. 2009, 2011) at a speed of $2-5$ knots.

From this existing dataset, we selected tag deployments with at least 18 bubble-feeding events with concurrent prey data recorded that day, for analysis of the presence of a spatially nested hierarchy of foraging and prey distribution.

\section{Whale behavior data analysis}

To determine bubble-feeding event locations, each whale's 3-dimensional track was reconstructed using the tag's movement and orientation data. Assuming a constant swimming speed of $1 \mathrm{~m} \mathrm{~s}^{-1}$ (Wiley et al. 2011), the position of the whale was dead-reckoned 5 times $\mathrm{s}^{-1}$, starting at the GPS location of the tag deployment. The resolution of each resulting pseudotrack was then down-sampled to 1 location $\mathrm{s}^{-1}$, and its spatial accuracy was improved by geo-referencing the pseudotrack to the GPS positions of the whale recorded at the surface using the R package 'Bayesian AnimalTracker' (Liu et al. 2015). During this process, the number of triangulated positions approximated by the tag-based whale locations was maximized (Liu et al. 2015), thereby reducing the effect of inaccurate, outlying triangulated positions. The most likely location for each whale within a $95 \%$ credible interval was then calculated at every second (Liu et al. 2015).

Using the focal follow data, the times of bubblefeeding events were determined. While different behavioral sequences can occur during bubble-feeding (Wiley et al. 2011), we analyzed all bubble-feeding events equally. To identify feeding events missed during the behavioral observations, the dead-reckoned track was visualized using TrackPlot software (Ware et al. 2006), and bubble-feeding events were identified based on characteristic loops in the track and intense body rolls of the whale (Hazen et al. 2009, Wiley et al. 2011), and their times noted. The geo-referenced track of the whale was then used to determine the location of the whale at the time of every recorded feeding event.

To aggregate each whale's feeding events into bouts, the distances between sequential feeding events were calculated. Kernel densities of these distances were estimated, and the break following the first peak in the kernel density curve was identified. Sequential feeding events separated by distances shorter than the distance at the break were grouped together into larger feeding bouts (Benoit-Bird et al. 2013). The size of each bout was calculated as the greatest of all pairwise distances between feeding events within each bout. The distance between sequential bouts was calculated as the shortest of all pairwise distances between feeding events from the 2 bouts. 
To investigate the influence of the social context of the tagged whales on feeding bout geometry, we identified the number of animals associated with the tagged whale for each feeding event whenever possible. We calculated the average number of associates during feeding events, as well as the largest number of associates during a feeding event, for all feeding events with a known number of associates, for each whale. Unless explicitly stated as surfacing in the feeding bubbles of the tagged whale in the behavioral observations, we did not consider calves as associates during feeding events, because it was unlikely that they were actively participating in bubble-feeding.

\section{Prey data analysis}

Data from the RV 'Auk' mapping the fine-scale prey distribution within an approximately $500 \mathrm{~m}$ radius around the tagged whales was visualized using the software Echoview (version 5). All data $<3.5 \mathrm{~m}$ from the surface and $<2 \mathrm{~m}$ of the sea floor, as well as regions with incomplete data, were excluded from further analyses. A school detection algorithm (Coetzee 2000) was run to detect schools comparable to a visual analysis of the data (maximum vertical linking distance of $10 \mathrm{~m}$ and a maximum horizontal linking distance of $20 \mathrm{~m}$ based on previous analyses). The detected schools were visually scrutinized, and schools missed by the algorithm were added manually. As the only common forage fish of humpback whales in the area without a swimbladder, schools of sand lance Ammodytes spp. could be identified based on higher acoustic backscattering coefficients on the $120 \mathrm{kHz}$ echogram compared to the $38 \mathrm{kHz}$ echogram (Yasuma et al. 2009), as well as their shape and location in the water column. For each sand lance school, data from the $120 \mathrm{kHz}$ echogram was exported for further analysis, including mean length of the school as well as geographic coordinates of the school center and the time the school was recorded. Since actual school geometry is unknown, the length of each school determined by the acoustic data does not necessarily reflect the longest horizontal extent of the school, but simply the horizontal extent captured by the echosounder beam. However, because all schools were orientated randomly relative to the path of the prey-mapping ship, the mean of the school length measured by the echosounder data is likely an accurate representation of a mean horizontal bisection of a given school.
For each prey-mapping day, the distances between schools along the track of the prey-mapping ship were calculated. Since prey-mapping occurred in a single, linear dimension along the track of the prey-mapping ship, the distances between prey schools calculated here are the distances between sequentially recorded schools along the track of the prey-mapping ship, hereafter referred to as neighboring schools. Kernel densities of these distances were estimated, and the break following the first peak in the kernel density curve was identified. Neighboring schools separated by distances shorter than the distance at the break were grouped together into larger sand lance patches (Benoit-Bird et al. 2013). The size of each patch was calculated as the greatest of all pairwise distances between schools within each patch. The distance between neighboring (i.e. sequentially recorded) patches was calculated as the shortest of all pairwise distances between schools from the 2 patches.

\section{Comparison of feeding bout and sand lance patch geometry}

To visually compare bubble-feeding bout size to sand lance patch size, kernel densities of the bout sizes of each whale were estimated and plotted against the estimated kernel densities of sand lance patch sizes calculated for the day the whale was tagged. To visually compare the distances between sequential bubble-feeding bouts to the distances between sequentially recorded sand lance patches, kernel densities of inter-bout distances of each whale were estimated and plotted against the estimated kernel densities of distances between sand lance patches.

\section{Comparison of feeding event distances to prey school distances and lengths}

For each tagged whale and the prey field recorded that day, cumulative distribution functions of distances between sequential bubble-feeding events, distances between neighboring sand lance schools and school lengths, were plotted together. Twosided, 2-sample Kolmogorov-Smirnov tests were run in RStudio (RStudio Team 2016) to compare the distribution of feeding event distances to the distribution of school distances, and to the distribution of school lengths. 


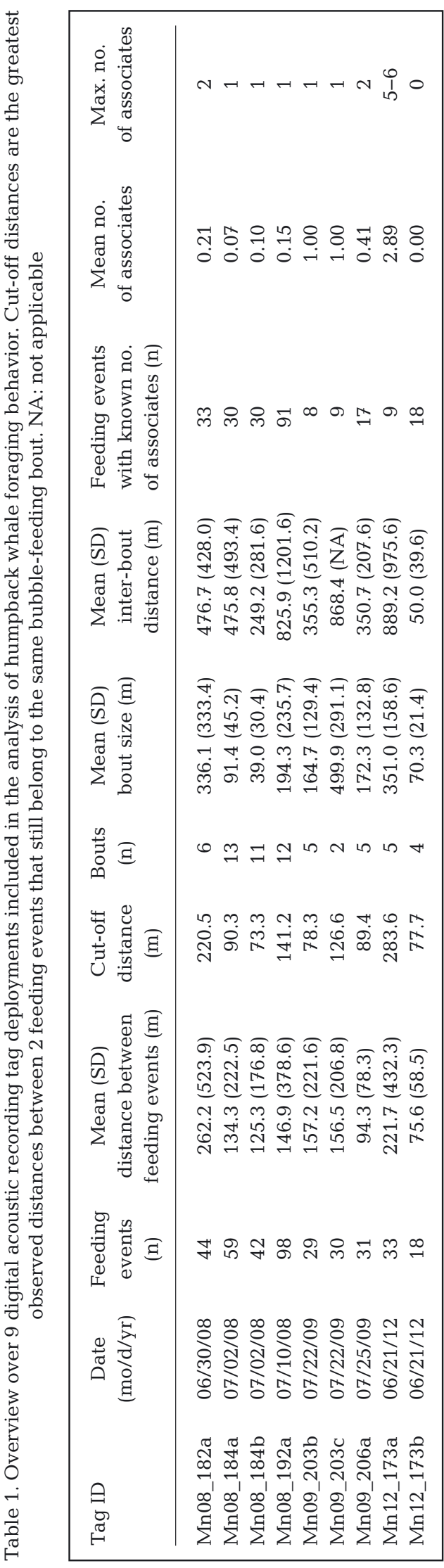

\section{RESULTS}

Data on 384 bubble-feeding events from 9 humpback whales Megaptera novaeangliae tagged on 6 days in 2008, 2009 and 2012 were included in the analysis (Table 1, Fig. 1). Distances between sequential feeding events ranged from 2.7 to $3108.0 \mathrm{~m}$. Based on breaks in the kernel density curves of feeding event distances (Fig. 2), bubble-feeding events were grouped into between 2 and 13 bouts. These bouts comprised between 2 and 37 feeding events and ranged from 5.8 to $758.6 \mathrm{~m}$ in size (Fig. 3). Distances between sequential bouts ranged from 8.0 to $3998.0 \mathrm{~m}$ (Fig. 4). Associations of tagged whales often changed during tag deployments. The average number of whales associated with the tagged whales ranged from 0.00 to 2.89 , and the maximum number of associates during a feeding event ranged from 0 to 6 (Table 1).

On the 6 days included in the analysis, 1040 sand lance Ammodytes spp. schools were recorded (Table 2). School lengths ranged from 0.3 to $1255.0 \mathrm{~m}$ (Fig. 5). Horizontal distances to neighboring schools ranged from $0.0 \mathrm{~m}$ (vertically separated schools) to $2444.0 \mathrm{~m}$. Based on the breaks in the kernel density curves of neighboring school distances (Fig. 2), schools could be grouped into between 5 and 42 patches. Patches comprised between 2 and 109 schools and ranged from 9.6 to $2295.0 \mathrm{~m}$ in size (Fig. 3). Distances between neighboring patches ranged from 17.8 to 2377.0 m (Fig. 4).

Sand lance patches spanned a wider range of sizes than the bubble-feeding bouts recorded each day (except for whale Mn08_192a), and bubble-feeding bout sizes tended to be on the lower end of the range of sand lance patch sizes recorded on the same day. For 7 out of 9 whales, at least 1 bubble-feeding bout scale (either bout sizes or inter-bout distances) corresponded to at least 1 prey patch scale (either patch sizes or inter-patch distance) (Table 3). For 5 out of 9 whales, 1 bout size scale corresponded to 1 scale of sand lance patch size (Fig. 3). For 1 whale (Mn08_182a), both observed scales of bubble-feeding bout size corresponded to 2 out of 3 scales that characterized the sand lance patch sizes that day. For 4 out of 9 whales, distances between feeding bouts corresponded to distances between prey patches recorded that day on 1 spatial scale (Fig. 4). For 1 whale (Mn08_182a), all 3 scales of feeding bout distances corresponded to scales of prey patch distances.

For all 9 whales, the distribution of feeding event distances was more similar to the distribution of school distances $(0.11 \leq \mathrm{D} \leq 0.34$, Fig. 5$)$ than to the distribution of school lengths $(0.26 \leq \mathrm{D} \leq 0.67$, Fig. 5), 


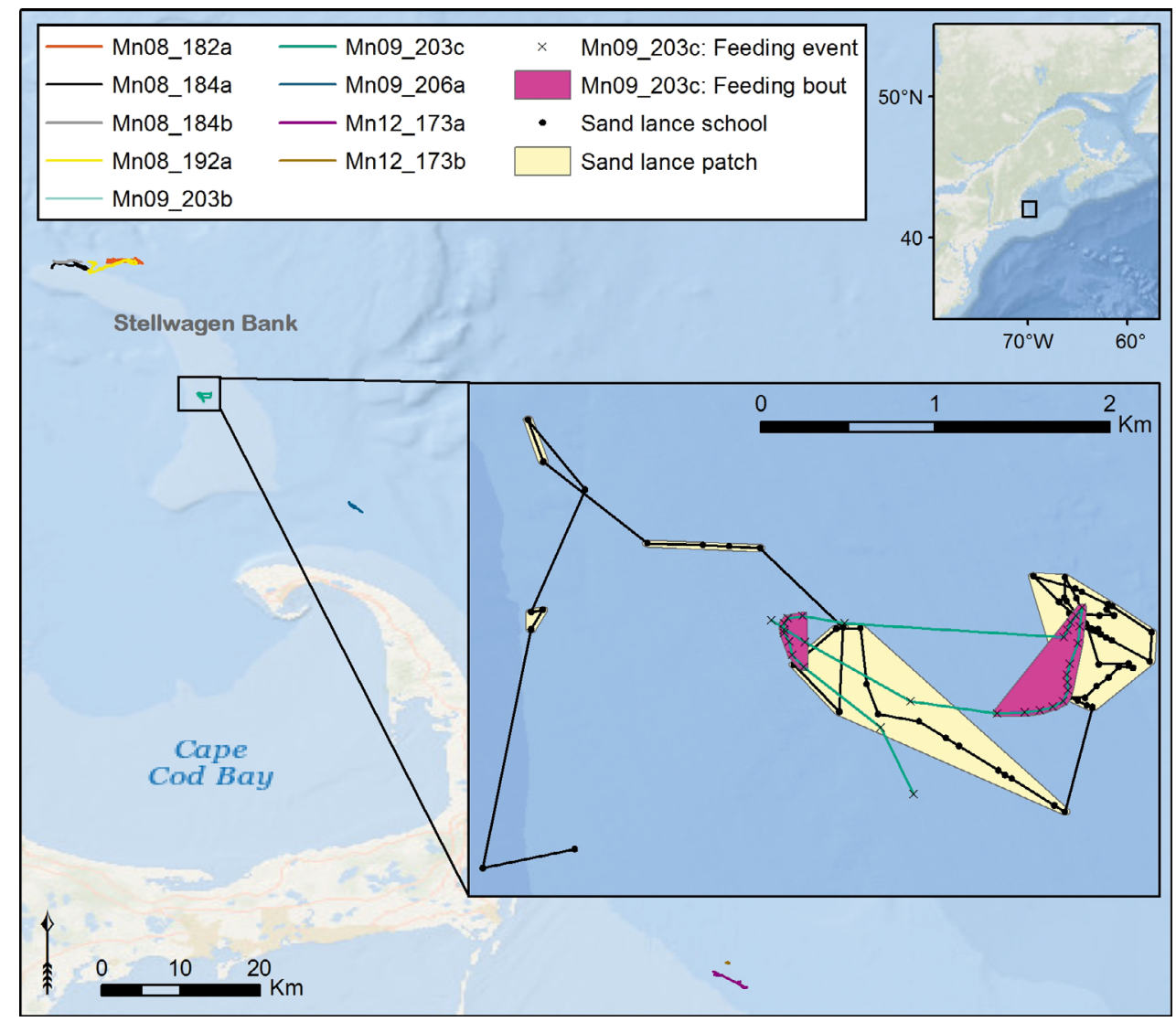

Fig. 1. Locations of bubble-feeding activity by humpback whales during the analyzed tag deployments. Colored lines connect sequential feeding events of each whale. Large inset shows detailed view of whale Mn09_203c (green line). The black line connects sequentially recorded sand lance schools around Mn09_203c. The polygons show the grouping of bubble-feeding events into larger bouts and of sand lance schools into larger patches. Small inset shows the location of the study area on Stellwagen Bank in the southern Gulf of Maine, USA

with feeding event distances being significantly different $(\mathrm{p}<0.05)$ from school lengths for all whales. For 2 out of 3 whales for which feeding event distances were significantly different from neighboring school distances (Mn08_184a, Mn09_203b), feeding event distances tended to be shorter than school distances, but longer than school lengths, at small to intermediate scales (between 10 and 200 m). For Mn12_173a, feeding event distances tended to be greater than both school lengths and neighboring school distances over all but the smallest scale $(<10 \mathrm{~m})$.

\section{DISCUSSION}

Currently, little is known about how intermittent suspension-feeders move within and between patches of mobile prey in marine systems. Combining fine-scale data on humpback whale foraging movement with measurements of the surrounding prey distribution, we observed spatially nested, hierarchical whale foraging movement on scales that corresponded to scales observed in the hierarchical geometry of prey fish schools and patches recorded around the tagged whales.

The complex sand lance patch geometry that we observed during each day of our study was likely the result of a combination of spatial proximity to both suitable benthic burial and productive pelagic foraging habitat of the sand lance (van der Kooij et al. 2008). Due to their high benthic habitat specificity targeting particular substrate compositions in certain hydrological conditions within a specific depth range (Wright et al. 2000), benthic habitat suitable for sand lance burying is likely very heterogeneously distributed in the study area (Scott 1968, Robards et al. 1999). Hazen et al. (2009) found that pelagic sand lance biomass in SBNMS was highest near the steep western slope of Stellwagen Bank, where the interaction of tidally driven currents with the slope creates 


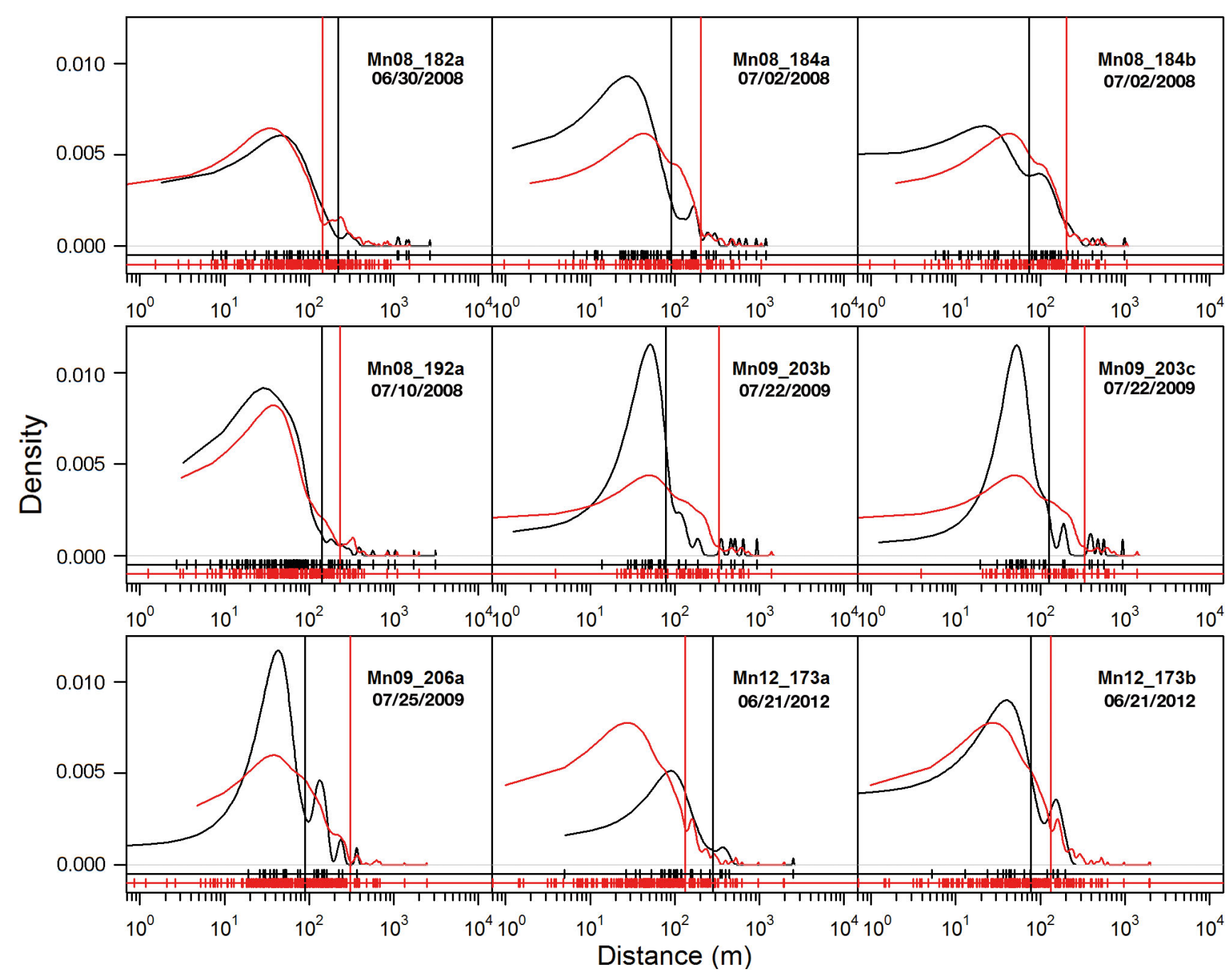

Fig. 2. Kernel density estimates of distances between sequential bubble-feeding events (black) and distances between neighboring sand lance schools (red), for each tagged humpback whale and the prey field recorded that day. Tick marks below each panel indicate the locations of the data points. Vertical lines indicate cut-off distances for feeding bout and sand lance patch formation. Dates given as $\mathrm{mo} / \mathrm{d} / \mathrm{yr}$

internal waves that can aggregate zooplankton and, consequently, sand lance (Haury et al. 1979). Since we conducted the majority of prey mapping on or near Stellwagen Bank, the scales of sand lance aggregations associated with suitable benthic and pelagic habitat on the Bank were likely the main drivers of the sand lance patch scales quantified here.

The correspondence of bubble-feeding scales to scales of the surrounding prey field, which we observed in the vast majority $(77.8 \%)$ of whales in our study, resulted from energetically efficient foraging movement of the tagged whales within and beween prey patches. Bubble-feeding bout sizes were of the same size as, or smaller than, sand lance patches, suggesting that the whales restricted their foraging activity to within the confines of the prey patches they were exploiting (Bell 1991). In this way, foraging activity in areas of less dense prey school aggregations could be reduced, and foraging efficiency increased (Charnov 1976). Fauchald \& Tveraa (2006) suggested that the scales of foraging movement of individual Antarctic petrels were likely smaller than the sizes of their prey patches, as they might not explore the entire patch area. Likewise, feeding bouts smaller than prey patches could result from the whales abandoning patches before moving through the entire patch, possibly resulting from satiation or disturbance of the foraging activity, or from a depression of resources in the patch below a profitable level (Charnov 1976, Charnov et al. 1976). Therefore, in cases where feeding bouts were smaller than prey patches, the resulting lack of correspondence of feed- 

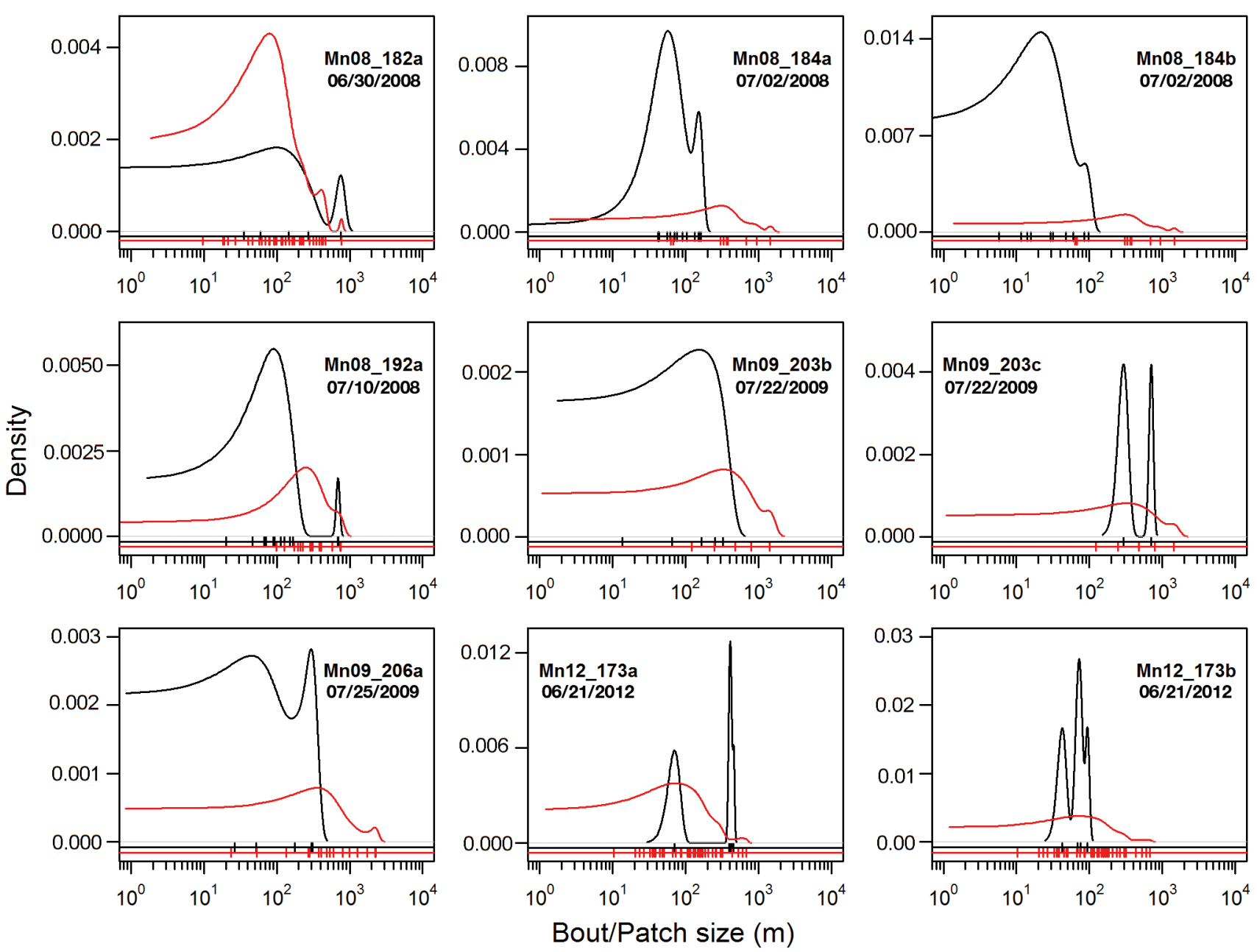

Fig. 3. Kernel density estimates of bubble-feeding bout (black) and sand lance patch (red) size for each tagged humpback whale and the prey field recorded that day. Tick marks below each panel indicate the locations of the data points

ing bout size to prey patch size does not necessarily indicate energetically inefficient whale movement, or a lack of adaptation of whale foraging movement to the structure of the prey field.

Similarities in the distances between sequential bubble-feeding bouts and neighboring prey patches suggest that upon terminating a feeding bout in one patch, the whales concentrated their foraging effort on the neighboring patch. In this way, the whales could minimize energy spent on travel between patches, and increase their foraging efficiency (Charnov 1976). In the 4 cases where the greatest distance between sequential bouts exceeded the greatest distance between neighboring prey patches recorded that day, an increased level of satiation following the termination of a feeding bout (Beukema 1968) or communication with other foraging conspecifics might have resulted in the whale moving past the nearest patch. However, such movement could also indicate active prey patch selection by the whales, or that the ability of the whales to locate the nearest patch is reduced at these large spatial scales.

The correspondence of bubble-feeding bout geometry to prey geometry appeared to be independent of the associations of the tagged whale with other whales. Group size differed greatly for 2 whales tagged on the same day: Mn12_173a and Mn12_173b. Considering all feeding events with known group size, Mn12_173a was feeding in the largest group included in our analysis with the highest average number of associates, while Mn12_173b was always feeding alone. Yet, the approximate scale of correspondence of feeding bout and prey patch size was similar for these whales. Mn08_184a and Mn08_184b were tagged on the same day and had comparable social contexts. Both whales were mostly feeding 

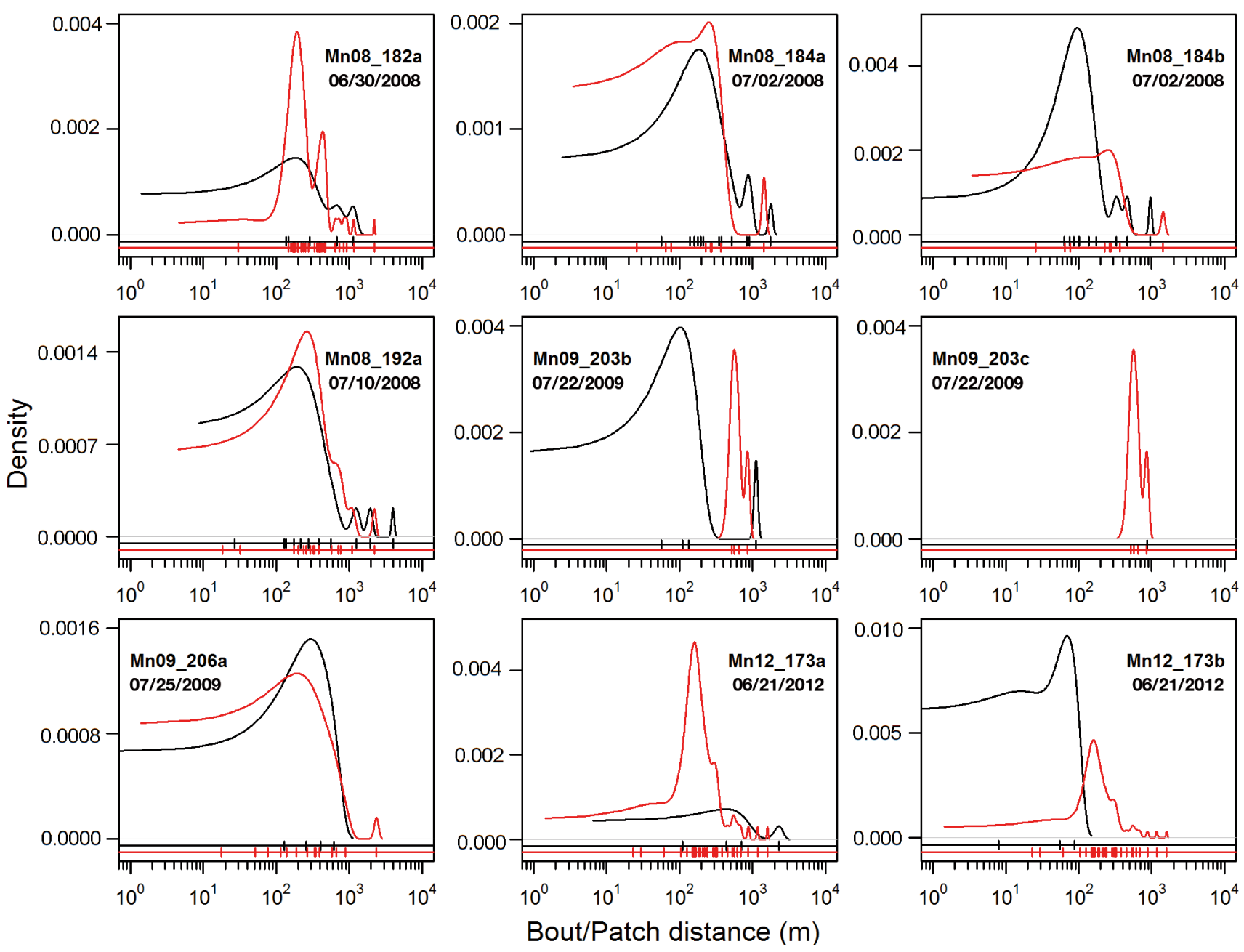

Fig. 4. Kernel density estimates of distances between sequential bubble-feeding bouts (black) and neighboring sand lance patches (red) for each tagged humpback whale and the prey field recorded that day. Tick marks below each panel indicate the locations of the data points

Table 2. Overview over prey field recorded around tagged humpback whales. Cut-off distances are the greatest observed distances between 2 schools that still belong to the same patch

\begin{tabular}{|lcccrrrr|}
\hline $\begin{array}{l}\text { Date } \\
(\mathrm{mo} / \mathrm{d} / \mathrm{yr})\end{array}$ & $\begin{array}{c}\text { Schools } \\
\text { recorded } \\
(\mathrm{n})\end{array}$ & $\begin{array}{c}\text { Mean (SD) } \\
\text { school } \\
\text { length (m) }\end{array}$ & $\begin{array}{c}\text { Mean (SD) } \\
\text { distance between } \\
\text { schools (m) }\end{array}$ & $\begin{array}{c}\text { Cut-off } \\
\text { distance } \\
(\mathrm{m})\end{array}$ & $\begin{array}{c}\text { Patches } \\
(\mathrm{n})\end{array}$ & $\begin{array}{c}\text { Mean (SD) } \\
\text { patch size } \\
(\mathrm{m})\end{array}$ & $\begin{array}{c}\text { Mean (SD) } \\
\text { inter-patch } \\
\text { distance }(\mathrm{m})\end{array}$ \\
\hline $06 / 30 / 08$ & 191 & $49.3(71.3)$ & $155.3(203.1)$ & 143.1 & 37 & $171.6(161.7)$ & $38.4(32.1)$ \\
$07 / 02 / 08$ & 123 & $50.4(54.7)$ & $116.9(135.6)$ & 202.3 & 9 & $509.6(450.3)$ & $40.8(36.5)$ \\
$07 / 10 / 08$ & 146 & $35.8(36.6)$ & $123.7(209.3)$ & 232.5 & 16 & $359.0(205.3)$ & $24.6(24.1)$ \\
$07 / 22 / 09$ & 63 & $45.2(47.9)$ & $191.4(225.7)$ & 331.6 & 5 & $615.7(524.0)$ & $112.3(95.7)$ \\
$07 / 25 / 09$ & 284 & $44.1(60.4)$ & $136.5(196.3)$ & 304.6 & 16 & $781.6(734.7)$ & $37.5(41.5)$ \\
$06 / 21 / 12$ & 233 & $58.0(124.4)$ & $119.3(209.7)$ & 132.4 & 42 & $167.0(157.0)$ & $30.8(31.6)$ \\
\hline
\end{tabular}

alone and were only occasionally joined by another whale. While inter-bout distances of Mn08_184a corresponded to inter-patch distances recorded that day, neither of the 2 whales showed correspondence of bout size to prey patch size on the scales we investi- gated. Our results suggest that the observed social context of the tagged whales did not notably influence the observed bubble-feeding bout geometry.

The spatial and temporal limitations of our sampling methods likely restricted the spatial scales we 


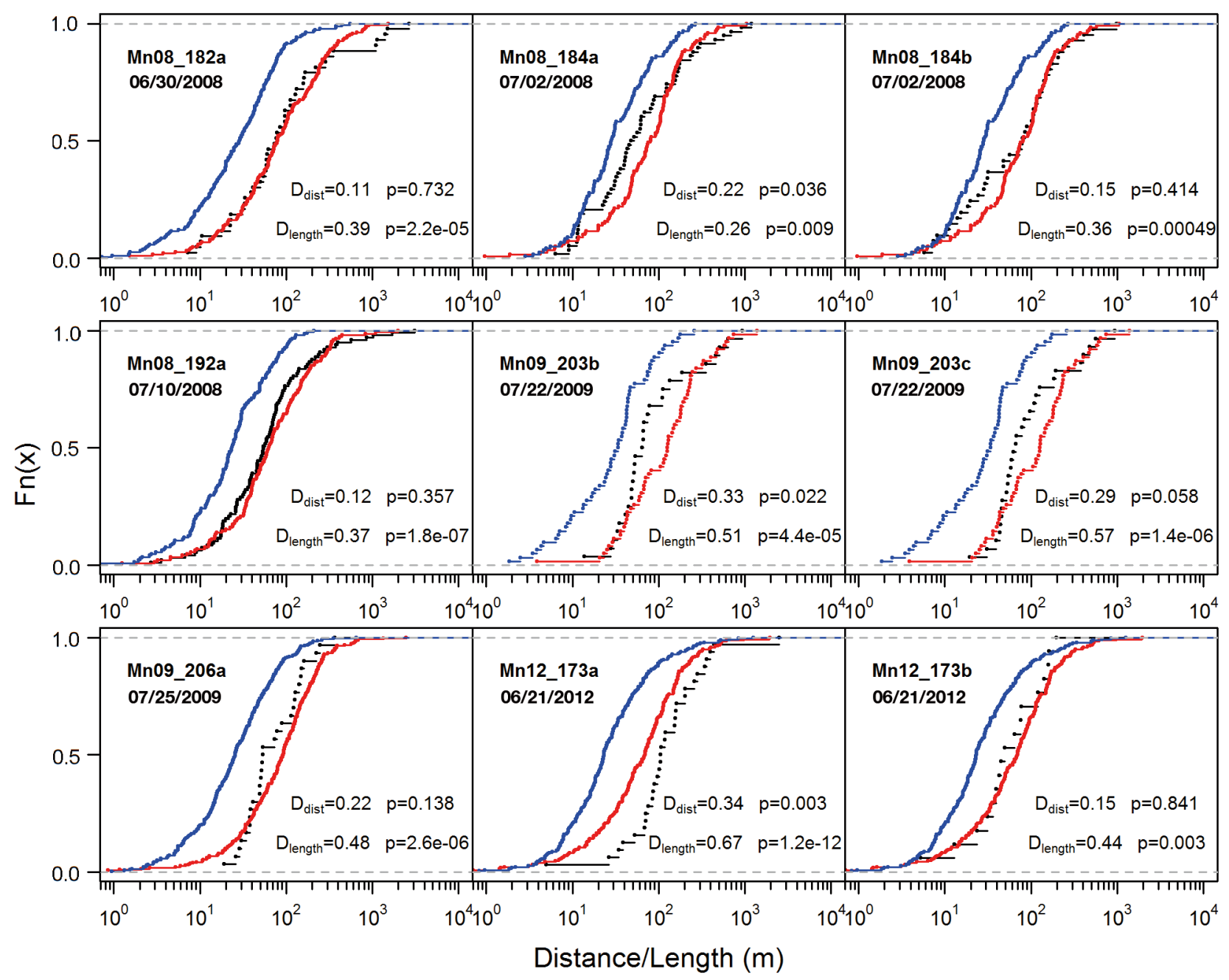

Fig. 5. Cumulative distribution functions of distances between sequential bubble-feeding events (black), distances between neighboring sand lance schools (red) and sand lance school lengths (blue), for each tagged humpback whale and the prey field recorded that day. Each panel gives the test statistic and p-value of the Kolmogorov-Smirnov test comparing the distances between sequential bubble-feeding events of each whale to the distances between neighboring sand lance schools $\left(D_{\text {dist }}\right)$ and school lengths $\left(\mathrm{D}_{\text {length }}\right)$ recorded that day

Table 3. Correspondence of the sizes of bubble-feeding bouts and distances between sequential bubble-feeding bouts of humpback whales to the sizes of sand lance patches and distances between neighboring patches. NA: not applicable

\begin{tabular}{|lcc|}
\hline Tag ID & $\begin{array}{c}\text { Approx. scale of } \\
\text { correspondence of } \\
\text { bout and patch sizes (m) }\end{array}$ & $\begin{array}{c}\text { Approx. scale of } \\
\text { correspondence of bout } \\
\text { and patch distance (m) }\end{array}$ \\
\hline Mn08_182a & 100,750 & 200, 700-800, 1150 \\
Mn08_184a & NA & 200 \\
Mn08_184b & NA & NA \\
Mn08_192a & 700 & 200 \\
Mn09_203b & NA & NA \\
Mn09_203c & 300 & $800-900$ \\
Mn09_206a & 300 & $200-300$ \\
Mn12_173a & 70 & NA \\
Mn12_173b & 70 & NA \\
\hline
\end{tabular}

were able to record. Maximum tag deployment duration was determined by pre-programmed tag release; however, factors influencing tag adhesion, such as surface active behavior of the tagged whales, shortened the deployment duration of several tags, thereby likely limiting the observed spatial scales of bubble-feeding bouts. The spatial extent of our prey mapping activity did not cover the full expanse of the $39 \mathrm{~km}$ long Stellwagen Bank, and therefore likely did not cover the full extent of sand lance aggregations promoted by hydrodynamic effects along its western edge. Additionally, prey mapping was occasionally interrupted by periods of unfavorable sea state and need for fast transit of the prey-mapping vessel. Therefore, it is likely that 
larger, potentially corresponding, scales of bubblefeeding and sand lance aggregation exist for at least some of the whales in this study, that were not captured here.

Potentially confounding the observed spatial predator-prey relationship by introducing a temporal mismatch between the prey mapping and whale foraging data, the prey mapping often lagged behind the actual feeding locations, due to unpredictable whale movement. Consequently, we did not always map the prey in those patches visited by the tagged whale at the time of feeding. Assuming that the prey distribution was stable on a daily scale, we examined the overall effect of the prey field geometry on the overall geometry of bubble-feeding bouts during each deployment, thereby overcoming the need for strictly synoptic measurement of predator and prey behavior. The assumption of a static prey field during the spatial analysis of the prey data could potentially result in an overestimation in patch numbers or sizes, or an underestimation of inter-patch distances, especially on larger spatial scales. However, because our observations of correspondence of bubble-feeding scales to prey aggregation scales are spread across multiple independent prey mapping periods and across 3 different years, it is unlikely that this caveat influences the observed correlation between bubblefeeding and prey patch geometry.

The observed similarities in the distribution of distances between sequential feeding events and neighboring school distances, compared to the significant differences to school lengths, suggest that generally, sequential feeding events targeted neighboring prey schools, rather than the same schools repeatedly. An initial bubble-feeding event in a school may elicit predator avoidance behavior by the sand lance, reducing prey availability during subsequent bubblefeeding events targeting the same school (Charnov et al. 1976). This predator avoidance behavior may result in an increase in the horizontal and a decrease in the vertical extent of at least parts of the schools, as described for sand lance by Pitcher \& Wyche (1983). Such a school conformation would be less conducive to the bubble-feeding behavior of whales, as it has been observed previously that bubble-feeding effort was concentrated near vertically oriented schools (Hazen et al. 2009). Pitcher \& Wyche (1983) also described sudden increase in the distances among fish in a school as sand lance predator avoidance behavior. Such a school expansion would lead to a reduction in fish density in the school, and therefore a reduction in the net energy intake of a whale feeding on a school in this spatial configuration.
Despite the potential for resource depression in a sand lance school following a bubble-feeding event, our data indicate that sometimes, whales do appear to forage on the same school repeatedly. We observed this behavior by whales Mn08_184a and Mn09_203b. Mn09_203b was always associated with Mn09_203c, and for this whale, group foraging may have facilitated the exploitation of prey schools displaying predator avoidance behavior (Whitehead 1983, Clapham 1993, Wiley et al. 2011). Many other whales were observed in the area on the day that Mn08_184a was tagged, and, while mostly unassociated with the tagged animal, their presence in the area may have led to the tagged whale to remain with the same school for more than a single bubble-feeding event. Our data suggest that the presence of conspecifics, whether associated or unassociated with the tagged whales, may influence their movement between prey schools. Neither of the 2 whales tagged on 21 June 2012, the day with the highest mean and overall school length, appeared to forage in the same schools repeatedly, suggesting that repeated foraging in the same school may be independent of actual school length. While indeed, sequential feeding events of Mn12_173a appeared to target schools that were further apart than neighboring schools, these comparatively long feeding event distances could have resulted from changes in the position of the tagged whale in a large foraging group that was moving between neighboring schools. This whale was always observed feeding with other whales, in groups as large as 5 adult whales. Sequential feeding events of Mn12_173b, also foraging near the comparatively long schools recorded on this day, and the only whale in this study that was always observed feeding alone, appeared to target neighboring prey schools. Rather than resulting from an influence of school length on bubble-feeding movement, repeated foraging on the same school may be the result of group foraging behavior or the presence and behavior of conspecifics in the area.

Interestingly, the social context of the tagged whales observed in our study appeared to influence the movement between prey schools more than the correspondence of bubble-feeding bout geometry to prey patch geometry. Possibly, our study did not sufficiently capture the influence of far-away conspecifics on the movement of the tagged whales to observe effects on large-scale bubble-feeding bout geometry. However, it is possible that the influence of social context on whale foraging movement is greatest on shorter spatial scales, due to its potential to facilitate the exploitation of evasive prey schools. 
Our conclusion that the fast prey patch switching of whales feeding on sand lance is due to the predator avoidance behavior of their prey is supported by Owen et al. (2015). They observed that, in a year where fish was the predominant prey type, the movement of humpback whales feeding on fish was characterized by more linear movement, while whales feeding on comparatively immobile zooplankton in a year where krill was the predominant prey type repeatedly moved through the same area. The adaptation of their foraging movement to the behavior of the pursued prey type could account for the diverse foraging patterns of humpback whales (Wiley et al. 2011) and their successful, strong recovery from whaling (Stevick et al. 2003). Similar to this movement of humpback whales feeding on zooplankton, continuous suspension-feeding manta rays (Papastamatiou et al. 2012), basking sharks (Sims \& Quayle 1998) and right whales (Mayo \& Marx 1990) also showed sustained foraging in high-density patches of relatively immobile zooplankton. Such retention of predators in profitable patches may also be a successful strategy for predators feeding on mobile prey that are capable of predator avoidance, if the predators feed on one prey item at a time (Benoit-Bird et al. 2013, Carroll et al. 2017). In contrast to this sustained foraging in profitable patches, our results suggest that moving between single schools of fish may be a more successful foraging strategy for intermittent suspension-feeders foraging on mobile prey.

We have shown that the spatially nested scales of humpback whale foraging correspond to the spatially nested scales of aggregations of their prey, indicating that foraging humpback whales adapt their hierarchical foraging movement to the hierarchical structure of the prey field they encounter. Feeding on neighboring prey schools and patches can reduce time and energy expenditure during travel between schools and patches, and can increase net energy gain. Disturbances of the sand lance prey field that lead to a decrease in the number of sand lance schools and patches, and an increase in the distances between neighboring schools and patches, can reduce the time whales spend inside a patch, and increase the time they spend traveling between schools and patches. In this way, such prey field changes could negatively impact whale foraging efficiency, potentially leading to whales abandoning this important foraging habitat (Payne et al. 1990). During a period with comparatively low sand lance abundances on Stellwagen Bank, Weinrich et al. (1997) observed a temporary shift in the distribution of humpback whales in the southern Gulf of Maine from Stellwagen Bank to another feeding area with increased abundances of herring Clupea harengus.

Rapid switching between neighboring prey schools, rather than sustained foraging in the same prey patch, distinguishes the foraging movement of the whales in this study from that of other suspensionfeeding vertebrates, and is likely a result of a behavioral adaptation to the mobility of their prey. Our findings contribute to our understanding of how predators find prey and forage in dynamic 3-dimensional environments.

Acknowledgements. We thank the crew of the RV 'Auk' for their support, as well as the members of the tagging project. We thank the Volgenau Foundation, the Stellwagen Bank National Marine Sanctuary Foundation, the Office of Naval Research grant N00014-08-0630 (S.E.P. and D.N.W.), and the International Fund for Animal Welfare for financial support of the tagging project. The Marine Mammal Institute helped to support both T.K. and A.S.F. during this project. T.K. was supported by the William and Francis McNeil Fellowship Award from OSU's Hatfield Marine Science Center, the Thomas G. Scott Achievement Award and the Ecology of Marine Nekton Award from OSU. We thank Ben Sheldon, Robert Harcourt, Ian Jonsen and 3 anonymous reviewers for helpful comments on a previous version of this manuscript, and Robert Kennedy for advice during data analysis. All data were collected under U.S. National Marine Fisheries Service permit nos. 775-185 (Northeast Fisheries Science Center) and 605-1904 (Whale Center of New England).

\section{LITERATURE CITED}

Bailey H, Thompson P (2006) Quantitative analysis of bottlenose dolphin movement patterns and their relationship with foraging. J Anim Ecol 75:456-465

Bailey H, Mate BR, Palacios DM, Irvine L, Bograd SJ, Costa DP (2009) Behavioural estimation of blue whale movements in the Northeast Pacific from state-space model analysis of satellite tracks. Endang Species Res 10:93-106

Barange M, Miller DGM, Hampton I, Dunne TT (1993) Internal structure of Antarctic krill Euphausia superba swarms based on acoustic observations. Mar Ecol Prog Ser 99: 205-213

Bell WJ (1991) Searching behaviour: the behavioural ecology of finding resources. Chapman \& Hall, London

Benhamou S (1992) Efficiency of area-concentrated searching behaviour in a continuous patchy environment. J Theor Biol 159:67-81

* Benoit-Bird KJ, Battaile BC, Nordstrom CA, Trites AW (2013) Foraging behavior of northern fur seals closely matches the hierarchical patch scales of prey. Mar Ecol Prog Ser 479:283-302

*Beukema JJ (1968) Predation by the three-spined stickleback (Gasterosteus aculeatus L.): the influence of hunger and experience. Behaviour 31:1-125

Carroll G, Cox M, Harcourt R, Pitcher BJ, Slip D, Jonsen I (2017) Hierarchical influences of prey distribution on patterns of prey capture by a marine predator. Funct Ecol 31:1750-1760 
Charnov EL (1976) Optimal foraging, the marginal value theorem. Theor Popul Biol 9:129-136

* Charnov EL, Orians GH, Hyatt K (1976) Ecological implications of resource depression. Am Nat 110:247-259

Clapham PJ (1993) Social organization of humpback whales on a North Atlantic feeding ground. Symp Zool Soc Lond 66:131-145

* Coetzee J (2000) Use of a shoal analysis and patch estimation system (SHAPES) to characterise sardine schools. Aquat Living Resour 13:1-10

Eifler DA, Baipidi K, Eifler MA, Dittmer D, Nguluka L (2012) Influence of prey encounter and prey identity on arearestricted searching in the lizard Pedioplanis namaquensis. J Ethol 30:197-200

Fauchald P, Tveraa T (2006) Hierarchical patch dynamics and animal movement pattern. Oecologia 149:383-395

Fauchald P, Erikstad KE, Skarsfjord H (2000) Scale-dependent predator-prey interactions: the hierarchical spatial distribution of seabirds and prey. Ecology 81:773-783

Friedlaender AS, Hazen EL, Nowacek DP, Halpin PN and others (2009) Diel changes in humpback whale Megaptera novaeangliae feeding behavior in response to sand lance Ammodytes spp. behavior and distribution. Mar Ecol Prog Ser 395:91-100

Friedman M, Shimada K, Martin LD, Everhart MJ, Liston J, Maltese A, Triebold M (2010) 100-Million-year dynasty of giant planktivorous bony fishes in the Mesozoic seas. Science 327:990-993

Haury LR, Briscoe MG, Orr MH (1979) Tidally generated internal wave packets in Massachusetts Bay. Nature 278: 312-317

*Hazen EL, Friedlaender AS, Thompson MA, Ware CR, Weinrich MT, Halpin PN, Wiley DN (2009) Fine-scale prey aggregations and foraging ecology of humpback whales Megaptera novaeangliae. Mar Ecol Prog Ser 395:75-89

Hazen EL, Nowacek DP, St. Laurent L, Halpin PN, Moretti DJ (2011) The relationship among oceanography, prey fields, and beaked whale foraging habitat in the tongue of the ocean. PLOS ONE 6:e19269

Johnson MP, Tyack PL (2003) A digital acoustic recording tag for measuring the response of wild marine mammals to sound. IEEE J Oceanic Eng 28:3-12

Kareiva P, Odell G (1987) Swarms of predators exhibit 'preytaxis' if individual predators use area-restricted search. Am Nat 130:233-270

Liu Y, Battaile BC, Trites AW, Zidek JV (2015) Bias correction and uncertainty characterization of dead-reckoned paths of marine mammals. Anim Biotelem 3:51

* Mayo CA, Marx MK (1990) Surface foraging behaviour of the North Atlantic right whale, Eubalaena glacialis, and associated zooplankton characteristics. Can J Zool 68: 2214-2220

Owen K, Warren JD, Noad MJ, Donnelly D, Goldizen AW, Dunlop RA (2015) Effect of prey type on the fine-scale feeding behaviour of migrating east Australian humpback whales. Mar Ecol Prog Ser 541:231-244

Papastamatiou YP, DeSalles PA, McCauley DJ (2012) Arearestricted searching by manta rays and their response to spatial scale in lagoon habitats. Mar Ecol Prog Ser 456: 233-244

Payne P, Wiley D, Young S, Pittman S, Clapham P, Jossi J (1990) Recent fluctuations in the abundance of baleen whales in the southern Gulf of Maine in relation to changes in selected prey. Fish Bull 88:687-696
Pinaud D, Weimerskirch H (2005) Scale-dependent habitat use in a long-ranging central place predator. J Anim Ecol 74:852-863

Pitcher T, Parrish JK (1993) Functions of shoaling behaviour in teleosts, 2nd edn. Chapman \& Hall, London

Pitcher TJ, Wyche CJ (1983) Predator-avoidance behaviours of sand-eel schools: why schools seldom split. In: Noakes DLG, Lindquist DG, Helfman GS, Ward JA (eds) Predators and prey in fishes. Developments in environmental biology of fishes, Vol 2. Springer, Dordrecht, p 193-204

* Pyke GH, Pulliam HR, Charnov EL (1977) Optimal foraging: a selective review of theory and tests. Q Rev Biol 52: $137-154$

Reay PJ (1970) Synopsis of biological data on North Atlantic sandeels of the genus Ammodytes (A. tobianus, A. dubius, $A$. americanus and $A$. marinus). Food and Agriculture Organization of the United Nations, Rome

Robards MD, Willson M, Armstrong RH, Piatt J (1999) Sand lance: a review of biology and predator relations and annotated bibliography. U.S. Department of Agriculture, Forest Service, Pacific Northwest Research Station, Portland, OR

RStudio Team (2016) RStudio: integrated development for R. RStudio, Boston, MA

Sanderson S, Wassersug R (1993) Convergent and alternative designs for vertebrate suspension feeding. In: Hanken J, Hall BK (eds) The skull, Vol 3. Functional and evolutionary mechanisms. Chicago University Press, Chicago, IL, p 37-112

* Scott JS (1968) Morphometrics, distribution, growth, and maturity of offshore sand launce (Ammodytes dubius) on the Nova Scotia Banks. J Fish Res Board Can 25:1775-1785

Sih A (1984) The behavioral response race between predator and prey. Am Nat 123:143-150

* Sims DW, Quayle VA (1998) Selective foraging behaviour of basking sharks on zooplankton in a small-scale front. Nature 393:460-464

Steele JE (1978) Spatial pattern in plankton communities. Plenum Press, New York, NY

Stevick PT, Allen J, Clapham PJ, Friday N and others (2003) North Atlantic humpback whale abundance and rate of increase four decades after protection from whaling. Mar Ecol Prog Ser 258:263-273

*van der Kooij J, Scott BE, Mackinson S (2008) The effects of environmental factors on daytime sandeel distribution and abundance on the Dogger Bank. J Sea Res 60: 201-209

* van Gils JA, van der Geest M, De Meulenaer B, Gillis H, Piersma T, Folmer EO (2015) Moving on with foraging theory: incorporating movement decisions into the functional response of a gregarious shorebird. J Anim Ecol 84:554-564

*Viswanathan GM, Buldyrev SV, Havlin S, da Luz MGE, Raposo EP, Stanley HE (1999) Optimizing the success of random searches. Nature 401:911-914

*Ware C, Arsenault R, Plumlee M, Wiley D (2006) Visualizing the underwater behavior of humpback whales. IEEE Comput Graph Appl 26:14-18

Weimerskirch H, Pinaud D, Pawlowski F, Bost C (2007) Does prey capture induce area restricted search? A fine scale study using GPS in a marine predator, the wandering albatross. Am Nat 170:734-743

Weinrich MT, Malcom M, Griffiths R, Bove J, Schilling M (1997) A shift in distribution of humpback whales, Megaptera novaeangliae, in response to prey in the southern 
Gulf of Maine. Fish Bull 95:826-836

Whitehead H (1983) Structure and stability of humpback whale groups off Newfoundland. Can J Zool 61: 1391-1397

Wiley D, Ware C, Bocconcelli A, Cholewiak D, Friedlaender A, Thompson M, Weinrich M (2011) Underwater components of humpback whale bubble-net feeding. Behaviour 148:575-602

Wolanski E, Hamner WM (1988) Topographically controlled

Editorial responsibility: Peter Corkeron,

Woods Hole, Massachusetts, USA fronts in the ocean and their biological influence. Science 241:177-181

* Wright PJ, Jensen H, Tuck I (2000) The influence of sediment type on the distribution of the lesser sandeel, Ammodytes marinus. J Sea Res 44:243-256

* Yasuma H, Nakagawa R, Yamakawa T, Miyashita K, Aoki I (2009) Density and sound-speed contrasts, and target strength of Japanese sandeel Ammodytes personatus. Fish Sci 75:545-552

Submitted: April 17, 2018; Accepted: October 15, 2018

Proofs received from author(s): November 22, 2018 